Normalasari, et al/Jurnal Ekonomi Syariah Teori dan Terapan Vol. 6 No. 6 Juni 2019: 1178-1195; MODEL PROGRAM PEMBERDAYAAN EKONOMI DOMPET SOSIAL MADANI DALAM MEMBERDAYAKAN EKONOMI MASYARAKAT MUSLIM MELALUI PENGELOLAAN DANA ZAKAT,INFAQ DAN SHADAQAH (ZIS)

\title{
MODEL PROGRAM PEMBERDAYAAN EKONOMI DOMPET SOSIAL MADANI DALAM MEMBERDAYAKAN EKONOMI MASYARAKAT MUSLIM MELALUI PENGELOLAAN DANA ZAKAT, INFAQ DAN SHADAQAH (ZIS)'
}

\author{
Desy Intan Normalasari \\ Departemen Ekonomi Syariah-Fakultas Ekonomi dan Bisnis-Universitas Airlangga \\ Email: desydestan@gmail.com \\ Raditya Sukmana \\ Departemen Ekonomi Syariah-Fakultas Ekonomi dan Bisnis-Universitas Airlangga \\ Email: Raditya-s@feb.unair.ac.id
}

\begin{abstract}
:
This research aims to find out how economic empowerment program model of Dompet Sosial Madani goes on in empowering the economy of benefit recipients by funds management of zakat, infaq, and shadaqah. This research used qualitative-descriptive approach using case study strategy. Data collecting technique used is direct observation and being in the field of research. The results of the research shows that DSM did an accompaniment to the benefit recipients, while most of the assistances used infaq and shadaqah funds. The recipients accepted the assistances of business capital or business tools. By this existing program, the recipients hopefully will be able to empower themselves from being helpless to being useful to reach independency and welfare of their families.
\end{abstract}

Keywords: LAZ, Zakat, Productive Zakat, Empowerment Model.

\section{PENDAHULUAN}

Rukun Islam merupakan lima tindakan dasar dalam ajaran agama islam yang dianggap sebagai pondasi wajib bagi orang-orang yang beriman dan merupakan dasar bagi kehidupan semua umat muslim yang ada diseluruh dunia ini. Rukun Islam terdiri daripada lima perkara, yaitu:

1. Syahadat: menyatakan kalimat tiada Tuhan selain Allah, dan Muhammad itu utusan Allah.

2. Shalat: ibadah sembahyang lima waktu sehari.

3. Zakat: memberikan $2,5 \%$ dari uang simpanan kepada orang miskin atau yang membutuhkan.
4. Shaum atau Puasa : berpuasa dan mengendalikan diri selama bulan suci Ramadan.

5. Haji: pergi beribadah ke Mekkah, setidaknya sekali seumur hidup bagi mereka yang mampu.

Dari kelima rukun islam diatas zakat merupakan salah satu kewajiban muslim yang tidak hanya berhubungan dengan Allah semata (habluminnallah) tetapi zakat juga memiliki hubungan degan sesama manusia (habluminannas).

Allah swt telah memerintahkan kepada setiap umat muslim yang memilki harta mencapai nisab untuk mengelvarkan zakat hartanya setiap tahun. la berikan kepada yang berhak menerima dari kalangan fakir serta selain

\footnotetext{
${ }^{1}$ Jurnal ini merupakan bagian dari skripsi Desy Intan Normalasari, NIM: 04121 1431025, yang diuji pada tanggal 18 Januari 2019.
} 
Normalasari, et al/Jurnal Ekonomi Syariah Teori dan Terapan Vol. 6 No. 6 Juni 2019: 1178-1195; MODEL PROGRAM PEMBERDAYAAN EKONOMI DOMPET SOSIAL MADANI DALAM MEMBERDAYAKAN EKONOMI MASYARAKAT MUSLIM MELALUI PENGELOLAAN DANA ZAKAT,INFAQ DAN SHADAQAH (ZIS)

mereka yang zakat boleh diserahkan kepada mereka sebagaimana telah diterangkan dalam Al Qur'an. Di antara manfaat mengeluarkan zakat adalah untuk membantu orang-orang fakir dalam menutupi kebutuhan pokok sehari-hari mereka. Zakat juga memiliki peranan yang sangat strategis dalam upaya pengentasan kemiskinan atau pembangunan ekonomi. Berbeda dengan sumber keuangan untuk pembangunan yang lain, zakat tidak memiliki dampak baik apapun kecuali ridha dan mengharap pahala dari Allah swt semata. Dalam QS At Taubah 9:103 dimana artinya : "ambillah zakat dari sebagian harta mereka, dengan zakat itu kamu membersihkan dan mensucikan mereka dan mendoalah untuk mereka. Sesungguhnya doa kamu itu (menjadi) ketentraman jiwa bagi mereka. Dan Allah Maha mendengan lagi Maha mengetahui".

Namun demikian, bukan berarti mekanisme zakat tidak ada system kontrolnya. Nilai strategis zakat dapat dilihat melalui: Pertama, zakat merupakan panggilan agama. Kedua, sumber kevangan zakat tidak akan pernah berhenti. Artinya orang yang membayar zakat, tidak akan pernah berhenti dan akan terus membayar setiap tahun atau dalam suatu periode waktu yang telah ditentukan sesuai dengan ketetapan. Ketiga, zakat secara empiric dapat menghapus kesenjangan social dan sebaliknya dapat menciptakan restribusi aset dan pemerataan pembangunan. Agar menjadi sumber dana yang dapat dimanfaatkan bagi kesejahteraan masyarakat, terutama untuk mengentaskan kemiskinan dan menghilangkan kesenjangan sosial, maka perlu adanya pengelolaan zakat, infaq dan shadaqah secara professional dan bertanggung jawab yang dilakukan oleh masyarakat bersama Pemerintah, karena selain sebagai bentuk ibadah ritual, zakat juga mencakup dimensi sosial, ekonomi serta merupakan institusi yang akan menjamin terciptanya keadilan ekonomi dan kesejahteraan bagi masyarakat secara keseluruhan. Oleh karena itu, institusi zakat harus pula didorong untuk dapat menciptakan lapangan usaha produktif bagi kelompok masyarakat yang tidak mampu, Allah menjelaskan tentang zakat pada ayat Al Quran surat At Taubah ayat 60 .

Ada delapan orang yang termasuk dalam kelompok yang berhak menerima zakat. Kelompok yang behak menerima zakat yaitu fakir, miskin, amil atau pengurus zakat, mu'allaf, hamba sahaya, gharimin, fisabilillah, dan ibnus sabil. Zakat adalah ibadah yang memiliki peranan penting dalam segi ekonomi, sosial, budaya, serta agama yang berguna untuk mensejahterakan masyarakat. Dengan begitu terlihat jelas seberapa penting zakat berperan dalam kehidupan manusia. Zakat menjadi perwujudan ibadah kepada Allah SWT sekaligus sebagai perwujudan dari rasa 
Normalasari, et al/Jurnal Ekonomi Syariah Teori dan Terapan Vol. 6 No. 6 Juni 2019: 1178-1195; MODEL PROGRAM PEMBERDAYAAN EKONOMI DOMPET SOSIAL MADANI DALAM MEMBERDAYAKAN EKONOMI MASYARAKAT MUSLIM MELALUI PENGELOLAAN DANA ZAKAT,INFAQ DAN SHADAQAH (ZIS)

kepedulian sosial bagi sesama. Seseorang yang menunaikan zakat dapat mempererat hubungannya dengan Allah SWT maupun hubungannya kepada sesama manusia.

Di Indonesia, pengelolaan zakat diatur berdasarkan Undang-Undang Nomor 38 Tahun 1999 tentang Pengelolaan Zakat dengan Keputusan Menteri Agama (KMA) Nomor 581 Tahun 1999 tentang Pelaksanaan UndangUndang Nomor 38 Tahun 1999 dan Keputusan Direktur Jenderal Bimbingan Masyarakat Islam dan Urusan Haji No.D/291 tentang Pedoman Teknis Pengelolaan Zakat. Meskipun harus diakui bahwa dalam peraturan-peraturan tersebut masih banyak kekurangan yang sangat mendasar, misalnya tidak dijatuhkannya sanksi bagi muzakki yang melalaikan kewajibannya (tidak mau berzakat), tetapi undang-undang tersebut mendorong lahirnya amil zakat yang amanah,kuat dan dipercaya oleh masyarakat. Namun Undang-Undang Nomor 38 Tahun 1999 tentang Pengelolaan Zakat sudah tidak sesuai dengan perkembangan kebutuhan hukum dalam masyarakat saat ini sehingga perlu diganti dengan UU RI Nomor 23 tahun 2011 tentang Pengelolaan Zakat, undang-undang tersebut telah mengatur semua persoalan tentang zakat yang cukup sesuai dengan kebutuhan masyarakat saat ini.

Menindaklanjuti Keputusan Menteri Agama Nomor 37 Tahun 2003 tentang
Pelaksanaan Undang-Undang Nomor 38 Tahun 1999 tentang Pengelolaan Zakat. Dompet Sosial Madani Denpasar didirikan pada bulan Agustus 2001 yang telah mendapatkan rekomendasi MUI (Majelis Ulama Indonesia) Provinsi Bali sebagai Lembaga Amil Zakat Provinsi Bali. DSM Bali juga terdaftar pada DISKESOS Nomor: 466.3/486/BOPS/DISKESOS.

Dan berdasarkan Surat Keputusan (SK) Kementerian Agama Nomor: DJ.III/563 TAHUN 2016, Lembaga Amil Zakat (LAZ) Dompet Sosial Madani (DSM) Bali disahkan sebagai LAZ Tingkat Provinsi. Dengan ada SK tersebut, DSM Bali merupakan satusatunya LAZ Setingkat provinsi di Bali yang telah memenuhi syarat sebagai LAZ Provinsi dan menjadi keenam nasional LAZ Provinsi yang mendapatkan SK Kemenag RI. Maka dengan keluarnya Surat Keputusan ini, maka LAZ DSM Bali telah sah sebagai LAZ Provinsi di Provinsi Bali berdasarkan aturan baru UU No 23 Tahun 2011 (www.dompetsosial.id) yang bertujuan untuk memberikan pelayanan bagi masyarakat dalam menunaikan zakat dan lainnya sesuai dengan tuntunan agama Islam dan mengembangkan fungsi Badan Amil Zakat sebagai jaringan pengamanan sosial dalam rangka mensejahterakan masyarakat secara berkeadilan.

Penyaluran dana zakat melalui pemberdayaan di bidang ekonomi merupakan salah satu upaya untuk membangun daya (masyarakat) dengan mendorong, memotivasi dan 
Normalasari, et al/Jurnal Ekonomi Syariah Teori dan Terapan Vol. 6 No. 6 Juni 2019: 1178-1195; MODEL PROGRAM PEMBERDAYAAN EKONOMI DOMPET SOSIAL MADANI DALAM MEMBERDAYAKAN EKONOMI MASYARAKAT MUSLIM MELALUI PENGELOLAAN DANA ZAKAT,INFAQ DAN SHADAQAH (ZIS)

membangkitkan kesadaran akan potensi yang dimilikinya serta berupaya untuk mengembangkannya. Keberdayaan masyarakat adalah unsur dasar yang memungkinkan suatu masyarakat bertahan. Dalam pengertian yang dinamis, yaitu mengembangkan diri dan mencapai kemajuan. Keberdayaan masyarakat menjadi sumber dari apa yang dikenal sebagai Ketahanan Nasional.

Dompet Sosial Madani Denpasar menyalurkandana zakat, infaq dan shadaqah. Dimana selain menjadi badan penyalur dana zakat di DSM juga terdapat program yang terdiri dari program kemanusiaan, program pemberdayaan dan dakwah. yang salah satunya berupa program wirausaha Satu Keluarga Satu Usaha yang bertujuan untuk memfasilitasi masyarakat melalui Pemberdayaan ekonomi untuk mewujudkan kemandirian , dan kesejahteraan hidup yang lebih baik karena penyalurannya bersifat produktif dan disalurkan dalam bentuk bantuan modal usaha yang diberikan Dompet Sosial Madani kepada mustahia khususnya kaum lbu atau Wanita diharapkan dapat mengembangkan usaha dan bisa meningkatkan pendapatan mereka.

Pada tahun 2017 Bali mendapatkan penghargaan dari TripAdvisor yang meupakan salah satu situs penyedia berbagai informasi tentang turisme yang berpusat di Amerika Serikat memberikan penghargaan The World's
Best Destination kepada Bali dalam ajang TripAdvisor Travellers' Choice Award 2017. Penghargaan ini diberikan langsung oleh Head of Destination Marketing for TripAdvisor Asia Pacific Sarah Mathews kepada Gubernur Bali yang diwakili Asisten Gubernur bidang Perekonomian Administrasi Pembangunan Bapak Dewa Putu Sunarta di The Seminyak Beach Resort and Spa. Bali menerima penghargaan tersebut disbabkan pertumbuhan di aspek akomodasi sebanyak $25 \%$, daya tarik sebanyak $38 \%$, dan restoran sebanyak $38 \%$. (www.cnnindonesia.com)

Walaupun begitu, Potret wisata Bali terutama di daerah Badung dan sebagian Kota Denpasar, seakan mengisahkan Bali bebas dari kontaminasi virus kemiskinan. Sungguh, Bali dari tampilan wajah pariwisatanya, seakan meyakinkan pengunjung bahwa provinsi ini tidak lagi tersentuh kemiskinan. Namun jumlah penduduk miskin dibali cukup banyak ini dapat dilihat dari data badan pusat statistic provinsi bali tahun 2016 yaitu 178.18 ribu jiwa atau 4,25\%. (bps bali) dengan presentase penduduk miskin yang tersebar dibeberapa wilayah provinsi bali terbanyak terdapat pada kabupaten Karangasem $6,61 \%$, disusul dengan Klungkung $\quad 6,35 \% \quad$ Buleleng $5,79 \%$,Jembrana 5,33\% ,Bangli 5,22\% , Tabanan 5\% ,Gianyar 4,44\% ,Denpasar 2,15\% dan terakhir di Badung 2,06\%.

Lokasi penelitian berada di JIn. Diponegoro 218 Denpasar Bali, DSM Bali 
Normalasari, et al/Jurnal Ekonomi Syariah Teori dan Terapan Vol. 6 No. 6 Juni 2019: 1178-1195; MODEL PROGRAM PEMBERDAYAAN EKONOMI DOMPET SOSIAL MADANI DALAM MEMBERDAYAKAN EKONOMI MASYARAKAT MUSLIM MELALUI PENGELOLAAN DANA ZAKAT,INFAQ DAN SHADAQAH (ZIS)

memiliki penghimpunan dana paling besar pada dana Infaq, Zakat, Sedekah, dan Wakafnya. Menurut data tahun 2015, terdapat sedikitnya pendapatan DSM yaitu sekitar berjumlah Rp 4 Milyar per tahun dengan potensi zakat dibali sebesar 126 Milyar per tahun. Serta pendistribusian paling banyak untuk pemberdayaan ekonomi, kesehatan, pendidikan dengan memberikan beasiswa untuk dhuafa dan yatim.

Dengan hal tersebut, peneliti tertarik untuk melakukan penelitian pada DSM Bali maka dengan itu, berdasarkan latar belakang diatas, maka penelitian ini diberi judul "Model Program Pemberdayaan "Ibu Mandiri" Dompet Sosial Madani Denpasar dalam Memberdayakan Ekonomi Masyarakat Muslim melalui Pengelolaan Dana Zakat, Infaq dan Shadaqah."

II. LANDASAN TEORI

Model dalam Kamus Besar Bahasa Indonesia adalah pola (contoh,acuan,ragam dan sebagainnya) dari sesuatu yang akan dibuat atau dihasilkan. Pengertian yang sama model merupakan sebuah abstraksi dari sistem sebenarnya, dalam gambaran yang lebih sederhana serta mempunyai presentase yang bersifat menyeluruh.

Model Pemberdayaan merupakan suatu acuan bentuk atau pola pendampingan yang dilakukan agar mendapat bantuan pelayanan dalam hal pengetahuan dan ketrampilan. Indikator mutu program pemberdayaan adalah terjadinya perubahan perilaku, peningkatan penghasilan, bertambahnya wawasan dan keilmuan serta ketrampilan (skill). Pada akhirnya terwujud kemandirian (empowerment) sehingga fakir miskin terlepas dari kemiskinan dan ketergantungan. Bagi seorang pelaku perubahan, hal yang dilakukan terhadap individu, keluarga, kelompok atau komunitas adalah upaya memberdayakan dari keadaan tidak/kurang berdaya menjadi mempunyai daya guna mencapai kehidupan yang lebih baik (Ife,2002:53).

Menurut Suharto (2009:57) "Secara konseptual, pemberdayaan atau pemberkuasaan (empowerment), berasal dari kata "power" (kekuasaan atau keberdayaan)". Jadi dapat ditarik kesimpulan bahwa pemberdayaan merupakan kemauan dan kemampuan seseorang untuk bertindak atas kemauannya sendiri atas suatu hal yang ingin dikembangkan secara terus menerus dan lebih lanjut.

Hadi (2004:3) menjelaskan bahwa "pemberdayaan adalah suatu cara dengan nama rakyat, organisasi, dan komunitas diarahkan agar mampu menguasai (atau berkuasa atas) kehidupannya". Dengan kata lain pemberdayaan masyarakat merupakan upaya untuk memandirikan dan mensejahterakan masyarakat agar lepas dari jerat kemiskinan dengan tidak bergantung kepada orang lain. 
Normalasari, et al/Jurnal Ekonomi Syariah Teori dan Terapan Vol. 6 No. 6 Juni 2019: 1178-1195; MODEL PROGRAM PEMBERDAYAAN EKONOMI DOMPET SOSIAL MADANI DALAM MEMBERDAYAKAN EKONOMI MASYARAKAT MUSLIM MELALUI PENGELOLAAN DANA ZAKAT,INFAQ DAN SHADAQAH (ZIS)

Suharto (2009:99) menuliskan
bahwa "Pemberdayaan masyarakat
adalah sebuah konsep pembangunan
ekonomi yang merangkum nilai-nilai sosial.
Konsep ini membangun paradigm baru
dalam pembangunan, yakni bersifat
'people-centered, participatory, empowering, and sustainable'". konsep pemberdayaan yang dimaksud jauh lebih dari hanya menyediakan kebutuhan dasar berupa pangan,sandang, dan papan. Lebih dari itu konsep pemberdayaan adalah bagaimana upaya seseorang atau lembaga untuk mencegah kemiskinan di masa yang akan datang.

Suharto (2009: 102) menyebutkan dalam upaya pemberdayaan masyarakat dapat dilihat dari tiga sisi:

a. Menciptakan suasana atau iklim yang memungkinkan potensi masyarakat berkembang (enabling). Di sini titik tolaknya adalah pengenalan bahwa setiap manusia, setiap masyarakat, memiliki potensi yang dapat dikembangkan. Artinya tidak ada masyarakat yang sama sekali tanpa daya itu sendiri, dengan mendorong memotivasikan dan membangkitkan kesadaran akan potensi yang dimilikinya serta berupaya untuk mengembangkannya.

b. Memperkuat potensi atau daya yang dimiliki oleh masyarakat (empowering). Dalam rangka ini diperlukan langkahlangkah positif, selain dari hanya menciptakan iklim dan suasana.
Perbuatan ini juga meliputi langkahlangkah nyata, dan menyangkut penyediaan berbagai masukan atau (input), serta pembukaan akses kedalam berbagai peluang (opportunities) yang akan membuat masyarakat makin berdaya. Dalam upaya pemberdayaan ini, upaya yang amat pokok adalah meningkatkan taraf pendidikan, dan derajat kesehatan, serta akses kedalam sumber-sumber kemajuan ekonomi seperti modal, teknologi, informasi, lapangan kerja, dan pasar. Masukan pemberdayaan ini menyangkut pembangunan sarana dan prasarana dasar baik fisik, seperti irigasi, jalan, listrik, jembatan maupun sekolah, dan juga fasilitas pelayanan kesehatan, yang dapat dijangkau masyarakat pada lapisan paling bawah. Serta kesediaan lembaga-lembaga pendanaan, pelatihan,dan pemasaran di pedesaan. Dimana terkonsentrasi penduduk yang keberdayaannya amat kurang. Untuk itu, perlu ada program khusus bagi masyarakat yang kurang berdaya, karena program-program umum yang berlaku untuk semua, tidak selalu menyentuh pada lapisan masyarakat ini.

c. Memberdayakan mengandung pula arti melindungi, dalam proses pemberdayaan harus dicegah yang lemah menjadi bertambah lemah, oleh karena kekurang berdayaan dalam menghadapi yang kuat. 
Normalasari, et al/Jurnal Ekonomi Syariah Teori dan Terapan Vol. 6 No. 6 Juni 2019: 1178-1195; MODEL PROGRAM PEMBERDAYAAN EKONOMI DOMPET SOSIAL MADANI DALAM MEMBERDAYAKAN EKONOMI MASYARAKAT MUSLIM MELALUI PENGELOLAAN DANA ZAKAT,INFAQ DAN SHADAQAH (ZIS)

Menurut Ife dalam bukunya Miftachul Huda disebutkan bahwa "pemberdayaan ditujukan untuk meningkatkan kekuasaan (power)dari kelompok mayarakat yang kurang beruntung (disadvantage)'empowerment aims to increase the power of the disadvantage'". Penulis menyimpulkan dalam buku karangan Huda (2009 :272273) mengungkapkan pada dasarnya pemberdayaan menyangkut dua kata kunci yakni power dan disadvantage:

a. Kekuasaan (power)

Dalam masyarakat sering terjadi persaingan atau kompetisi yang tidak sehat antar kelompok yang satu dengan yang lainnya dan pada kondisi inilah yang lemah akan kalah. Untuk itu, para penguasa atau elit politik yang sekarng sdang mempunyai "power" harus mampu menghilangkan dominasi Antara salah satu kelompok agar terjadi keseimbangan.

b. Kekurang beruntungan (disadvantage)

$$
\text { Kekurang beruntungan adalah }
$$

sebab kekalahan kelompok dalam persaingan yang disebabkan oleh factor struktural, kultural, dan personal. Ketiga faktor tersebutlah yang menyebabkan kelompok mengalami kekurang beruntungan.

Yang dimaksud Huda kekuasaan adalah pemerintah namun lebih dari itu pemberdayaan dapat dilakukan oleh siapapun yang punya "power", keinginan, dan kepedulian terhadap sesamanya. Oleh karena itu diharapkan dengan adanya pemberdayaan, masyarakat dapat menjamin kehidupan dirinya sendiri dengan cara memanfaatkan potensi maupun sumber daya yang dimiliki untuk mewujudkan kesejahteraanya.

Praktik program pemberdayaan di bidang ekonomi menurut Kassam dalam Mardi (2008:18) meliputi : (1) bantuan modal bergulir, (2) bantuan pembangunan prasarana, pembangunan kelembagaan lokal, (4) penguatan pembangunan kemitraan usaha, dan (5) fasilitas dari pendampingan usaha. Adapun tujuan utama program pemberdayaan ekonomi yaitu memberdayakan individu-individu dan kelompok-kelompok orang melalui penguatan kapasitas (termasuk kesadaran, pengetahuan dan ketrampilan-ketrampilan) yang diperlukan untuk mengubah kualitas kehidupan komunitas mereka. Kapasitas tersebut seringkali berkaitan dengan penguatan aspek eonomi melalui pembentukan kelompok-kelompok sosial besar yang bekerja berdasarkan agenda bersama.

Islam pada dasarnya adalah agama pemberdayaan. Menurut pandangan Islam, pemberdayaan merupakan gerakan tanpa henti. Hal ini sejalan dengan paradigma Islam sendiri sebagai agama gerakan atau perubahan. Islam juga menekankan pentingnya pemberdayaan masyarakat lemah seperti anak yatim, fakir, dan miskin. Sebagaimana yang telah Allah SWT suratkan di dalam Al-Qur'an surat Al-Hasyr 
Normalasari, et al/Jurnal Ekonomi Syariah Teori dan Terapan Vol. 6 No. 6 Juni 2019: 1178-1195; MODEL PROGRAM PEMBERDAYAAN EKONOMI DOMPET SOSIAL MADANI DALAM MEMBERDAYAKAN EKONOMI MASYARAKAT MUSLIM MELALUI PENGELOLAAN DANA ZAKAT,INFAQ DAN SHADAQAH (ZIS)

ayat tujuh. Ayat tersebut menjelaskan bahwa pada zaman Rasulullah SAW Allah telah memerintahkan untuk membagikan harta rampasan yang dimiliki tersebut tidak kepada Rasul saja, melainkan diberikan juga kepaa penduduk, kaum kerabat, anak yatim, orang miskin, dan fisabilillah. Hal ini yang demikian tersebut telah jelas bahwa wajib mendistribusikan dan meratakan pendapatan agar kekayaan tidak terjadi disatu kalangan saja. Hal ini tentu dengan cara memberdayakan ekonomi yang sebanyak-banyaknya hingga kekayaan pun merata. Pengertian lain menjelaskan bahwa pemberdayaan atau pengembangan atau tepatnya pembangunan sumber daya manusia adalah upaya untuk memperluas horizon bagi masyarakat. Ini berarti masyarakat diberdayakan untuk melihat dan memilih sesuatu yang bermanfaat untuk dirinya sendiri. Memakai logika ini, dapat dikatakan bahwa masyarakat yang berdaya adlah yang dapat memilih dan mempunyai kesempatan untuk mengadakan pilihan.

Menurut Machendrawaty (2001:44) ada tiga macam pemberdayaan yang diperjuangkan dalam konteks keumatan masa kini, yakni pemberdayaan dalam tataran ruhaniah, intelektual, dan ekonomi. 1. Pemberdayaan pada ruhaniah

Pergeseran nilai masyarakat islam ini sangat mengguncang kesadaran Islam. Kepribadian kaum muslim terutama mayoritas generasi mudanya begitu mudah terpengaruh oleh budaya negative barat yang merupakan berlawanan dari nilai-nilai islam. Hal ini diperparah dengan gagalnya pendidikan agama hamper semua lini pendidikan.

Agar dapat keluar dari persoalan ini, masyarakat islam harus berjuang keras untuk melahirkan desain besar kurikulum pendidikan untuk setiap wilayah pendidikan, yang benar benar berorientas pada pemberdyaan total ruhaniyah Islamiyah yang tidak bertentangan dengan perjuangan kebenaran ilmiah dan kemodernan.

\section{Pemberdayaan intelektual}

Secara jelas dapat dirasakan umat islam yang ada di Indonesia bahkan di seluruh wilayah sudah tertinggal dalam kemajuan dan penguasaan teknologi. Maka diperlukan berbagai upaya pemberdayaan intelektual sebagai sebuah perjuangan besar.

3. Pemberdayaan ekonomi

Masalah kemiskinan menjadi demikian identik dengan masyarakat islam Indonesia. Pemecahannya, adalah tanggung jawab masyarakat islam sendiri, yang selama ini selalu terpinggirkan. Dalam konteks ekonomi, seorang putra islam dan generasi Qur'ani awal terbaik. Situasi masyarakat islam Indonesia bukan untuk diratapi, melainkan untuk dicarikan jalan pemecahannya. Upaya yang dapat dilakukan untuk keluar dari permasalahan eknomi ini, diperlukan perjuangan besar dan komitmen dari setiap komponen umat. Pribadi muslim ditantang untuk lebih 
Normalasari, et al/Jurnal Ekonomi Syariah Teori dan Terapan Vol. 6 No. 6 Juni 2019: 1178-1195; MODEL PROGRAM PEMBERDAYAAN EKONOMI DOMPET SOSIAL MADANI DALAM MEMBERDAYAKAN EKONOMI MASYARAKAT MUSLIM MELALUI PENGELOLAAN DANA ZAKAT,INFAQ DAN SHADAQAH (ZIS)

keras dalam bekerja, berkreasi dan berwirausaha, lebih-lebih dalam bekerja sama, komunikatif dalam berinteraksi, lebih terampil dalam memfasilitasi jaringan kerja, dan lebih professional dalam mengolah potensi-potensi dan kekuatankekuatan riil ekonomi umat. Agar dapat kelvar dari himpitan situasi ekonomi seperti sekarang. Di samping penguasaan terhadap ketrampilan hidup, ketrampilan berwirausaha, dibutuhkan juga pembangunan dan pemberdayaan ekonomi kerakyatan, yang selama ini tidak pernah bahkan jarang dilirik.

$$
\text { Dengan adanya kriteria }
$$

keberhasilan pemberdayaan yang digunakan untuk suatu proses evaluasi, Feurstein dalam Adi (2008: 23) mengajukan beberapa indikator yang perlu dipertimbangkan. Indikator dibawah ini adalah Sembilan indikator yang paling sering digunakan untuk mengevaluasi keberhasilan suatu kegiatan pemberdayaan yaitu:

1. Indikator Ketersediaan

Indikator ini melihat apakah unsur yang seharusnya ada dalam suatu proses itu benar ada.

2. Indikator Relevansi

Indikator ini menunjukkan seberapa relevan atau tepatnya suatu teknologi atau layanan yang ditawarkan.

3. Indikator Keterjangkauan

Indikator ini melihat apakah layanan yang ditawarkan masih berada dalam jangkauan pihak-pihak yang membutuhkan.
4. Indikator Pemanfaatan

Indikator ini melihat seberapa banyak suatu layanan yang diberi pihak pemberi layanan diterapkan atau dimanfaatkan kelompok sasaran.

5. Indikator Cakupan

Indikator ini menunjukkan proporsi orang-orang yang membutuhkan sesuatu dan menerima layanan tersebut.

6. Indikator Kualitas

Indikator ini menunjukkan kualitas dari layanan yang disampaikan ke kelompok sasaran.

7. Indikator Upaya

Indikator ini menggambarkan berapa banyak upaya yang sudah ditanamkan dalam rangka mencapai tujuan.

8. Indikator Efesiensi

Indikator ini menunjukkan apakah sumber daya dan aktivitas yang dilaksanakan guna mencapai tujuan dimanfaatkan secara efisien, atau tidak memboroskan sumber daya yang ada dalam upaya mencapai tujuan.

9. Indikator Dampak

Indikator ini melihat apakah sesuatu yang dilakukan oleh pihak pemberi layanan benar-benar memberikan sesuatu perubahan.

Tujuan kegiatan dalam jangka panjangnya adalah kemandirian yaitu pengembangan kapasitas dan pengitegrasian masyarakat yang dititik beratkan pada tujuan proses. Dalam penelitian ini menggunakan beberapa indikator yang digunakan untuk 
Normalasari, et al/Jurnal Ekonomi Syariah Teori dan Terapan Vol. 6 No. 6 Juni 2019: 1178-1195; MODEL PROGRAM PEMBERDAYAAN EKONOMI DOMPET SOSIAL MADANI DALAM MEMBERDAYAKAN EKONOMI MASYARAKAT MUSLIM MELALUI PENGELOLAAN DANA ZAKAT,INFAQ DAN SHADAQAH (ZIS)

mencapai keberhasilan dari penelitian ini, yaitu indikator pemanfaatan, kualitas, dampak serta transformasi mustahiq.

Setiap manusia memiliki keinginan untuk sejahtera, sejahtera menunjukkan ke suatu keadaan yang serba baik atau suatu kondisi manusia, dimana orangorang di dalamnya keadaan makmur, sehat, dan damai. Menurut Kamus Bahasa Indonesia, sejahtera juga mengandung pengertian aman sentosa, makmur, serta selamat terlepas dari segala macam gangguan.

Stiglitz (2011) menyatakan bahwa untuk mendefinisikan kesejahteraan rumusan multidimensi harus digunakan. Dimensi-dimensi tersebut meliputi: (1) standar hidup material (pendapatan, konsumsi, dan kekayaan); (2) kesehatan; (3) pendidikan; (4) aktivitas individu termasuk bekerja; (5) suara politik (data pemerintahan, hubungan dan kekerabatan sosial); (6) lingkungan hidup (kondisi sekarang dan masa depan) baik yang bersifat ekonomi maupun fisik. Semua dimensi ini menunjukkan kualitas hidup masyarakat dn untuk mengukurnya diperlukan data objektif dan subjektif.

Zakat dalam Al-qur'an disebutkan sebanyak 32 dan 82 kali diulang dengan menggunakan istilah yang sinonim dari kata zakat yaitu kata shodaqah dan infaq. Pengulangan tersebut mengandung maksud bahwa zakat mempunyai kedudukan, fungsi dan peran yang sangat penting di dalam slam. Hal ini menunjukkan bahwa islam sangat memperhatikan hubungan manusia dengan tuhan (hablun min Allah) dan hubungan dengan manusia (hablun min al-nas) (Ali, 2006:24).

Zakat (zakâh) secara bahasa bermakna "mensucikan", "tumbuh", atau "berkembang".menurut istilah syara', zakat bermakna mengeluarkan sejumlah harta tertentu untuk diberikan kepada orang-orang yang berhak menerimanya (mustahik) sesuai dengan syarat-syarat yang telah ditentukan oleh syariat islam. Zakat merupakan salah satu dari rukun islam yang kelima dan hokum pelaksanaannya adalah wajib. Zakat terbagi menjadi dua jenis, yaitu zakat jiwa (zakâh al-fithr) dan zakat harta (zakâh almâl). (Yusuf,2015:1)

$$
\text { Menurut Ryandono di dalam }
$$
ZISWAF (2008: 6) zakat adalah salah satu cara untuk mendistribusikan kekayaan (harta) dalam suatu perekonomian khususnya dari yang beruntung atau kaya kepada mereka yang tidak beruntung (miskin) dalam hal mencari riezeki.

Konsepsi zakat sebagai satu bagian dari rukun Islam yang mempunyai arti bahasa penyucian dan pertumbuhan, Allah SWT berfirman, "Sesungguhnya beruntunglah orang yang menyucikan jiwa itu", yaitu menyucikan kotoran atau dosa dalam dirinya (Nurul Huda, 2012: 88)Manusia benar-benar berada dalam keadaan yang merugi jika tidak tersentuh hatinya untuk bergerak menuju jalan Allah SWT, padahal petunjukNya telah nyata dengan jelas. Seperti halnya tersentuh hati 
Normalasari, et al/Jurnal Ekonomi Syariah Teori dan Terapan Vol. 6 No. 6 Juni 2019: 1178-1195; MODEL PROGRAM PEMBERDAYAAN EKONOMI DOMPET SOSIAL MADANI DALAM MEMBERDAYAKAN EKONOMI MASYARAKAT MUSLIM MELALUI PENGELOLAAN DANA ZAKAT,INFAQ DAN SHADAQAH (ZIS)

untuk bergerak memajukan ekonomi dijalan Allah SWT dan memakmurkan zakat. Sebagai prinsip yang dimiliki, zakat menurut M.A. Mannan dalam Nurul Huda (2012:89) terbagi menjadi 6 prinsip yaitu:

1. Prinsip keyakinan keagamaan

2. Prinsip pemerataan dan keadilan

3. Prinsip Produktivitas

4. Prinsip nalar

5. Prinsip kebebasan

6. Prinsip etika dan kewajaran.

Prinsip-prinsip diatas tidak lepas pada pandangan zakat menurut Al Quran, yaitu kewajiban bagi seluruh umat Muslim yang mampu untuk melakukan penyebaran harta agar tidak berputar pada satu golongan saja. Hal tersebut tertuang dalam rukun Islam dan memiliki kewajiban yang sama dengan shalat.

Dengan memunculkan pemikiran zakat adalah wajib hukumnya karena memiliki kewajiban yang sama dengan shalat, maka kaum Muslim seharusnya berfikir dan meyakini bahwa hal tersebut dapat dilakukan semua orang, orang kaya dan orang yang belum atau akan kaya. Sehingga dengan pemikiran tersebut, para mustahik dapat termotivasi untuk merubah statusnya menjadi muzaki, karena pada dasarnya, zakat adalah salah satu filantropi ekonomi Islam yang dapat memutar keadaan ekonomi seluruh umatnya menjadi lebih baik. (Kamil, 2016:145).

Menurut Amiruddin dkk (2005 :8) menjelaskan sebagai berikut: Infaq berasal dari kata "anfaqa" yang berarti mengeluarkan sesuatu (harta untuk kepentingan sesuatu. Sedangkan menurut terminology syariat, infaq berarti mengelvarkan sebagian harta atau pendapatan/ penghasilan untuk suatu kepentingan yang diperintahkan ajaran Islam. Jika zakat ada nishabnya, infaq tidak mengenal nishab. Infaq dikeluarkan oleh setiap orang yang beriman, baik yang berpenghasilan tinggi atau rendah. Jika zakat harus diberikan kepada mustahik tertentu (8 asnaf) maka infaq boleh diberikan kepada siapapun juga, misalnya untuk kedua orang tua, anak yatim, dan sebagainya. Infaq dapat digunakan untuk mengeluarkan sebagian kecil harta untuk kemaslahatan umum dan berarti sesuatu kewajiban yang dikeluarkan atas keputusan "manusia".

Dengan demikian, dapat dipahami bahwa infaq pada dasarnya sama dengan zakat yang diwajibkan atas harta yang harus dikeluarkan. Yang membedakan keduanya adalah zakat terdapat syarat, rukun, jenis, dan jumlahnya, sedangkan infaq tidak terdapat syarat, rukun, jenis dan dapat terus berkembang dan berubah menurut kepentingan maslahah mursalah.

Zakat wajib menurut bahasa juga disebut sedekah, sehingga Mawardi mengatakan, "Shadaqah itu zakat dan zakat itu shadaqah" berbeda nama tetapi arti sama (Qardawi, 1998 : 36) Allah SWT berfirman dalam Al-Qur'an surat At taubah ayat 58 . 
Normalasari, et al/Jurnal Ekonomi Syariah Teori dan Terapan Vol. 6 No. 6 Juni 2019: 1178-1195; MODEL PROGRAM PEMBERDAYAAN EKONOMI DOMPET SOSIAL MADANI DALAM MEMBERDAYAKAN EKONOMI MASYARAKAT MUSLIM MELALUI PENGELOLAAN DANA ZAKAT,INFAQ DAN SHADAQAH (ZIS)

Amiruddin (2005:13) menjelaskan sebagai berikut :Shadaqah atau sedekah berasal dari kata "shodaqah" yang berarti benar. Orang yang ska bersedekah adalah orang yang benar pengakuan imannya. Menurut terminology syariat, pengertian sedekah sama dengan pengertian infaq, termasuk juga hokum dan ketentuan-ketentuannya. Hanya saja, jika infaq berkaitan dengan materi, sedekah memiliki arti lebih luas, menyangkut hal yang bersifat non materiil.

Selain itu shadaqah merupakan pengertian yang sangat luas dimana terbagi menjadi dua yaitu yang bersifat material atau fisik dan bersifat non fisik.

1. Shadaqah material atau fisik

Shadaqah ini terdiri dari fardhu wajib dan sunnah, misalnya adalah zakat,infaq dan shadaqah.

2. Shadaqah non material

Shadaqah ini berupa tasbih, tasmid, tahlil, takbir, senyum, tenaga, menolong, menyuruh kepada kebaikan, dan menahan diri kepada kejahatan (Amiruddin et al $2005: 15$ ).

Atmosudirjo dalam buku Wursanto (2005:53) mendefinisikan organisasi itu sebagai sebuah struktur tata pembagian kerja dan struktur tata hubungan kerja antara sekelompok orang - orang pemegang posisi yang bekerjasama secara tertentu untuk bersama - sama mencapai tujuan tertentu.

Lembaga didalam bahasa inggris diartikan dengan "institution" mengandung berbagai pengertian seperti menurut James dalam kamus psikologi yang diterjemahkan oleh Nancy (1998:131) pengertian institusi yaitu: organisasi yang menggambarkan tahan kemajuan atau aspek kehidupan sosial, politik, keagamaan. Dengan kaidah hokum atau prinsp-prinsip dan hokumhukum dibawahnya dan aturan-aturan, atau sekelompok adat, kebiasaan,tetapi dalam semua hal memiliki derajat keabadian yang tidak dimiliki oleh kebiasaan atau adat.

Lembaga Amil Zakat (LAZ) dilihat dari beberapa teori yang ada, maka akan ditemukan hal serupa pada yaitu sekelompok orang yang bersama - sama bekerjasama melaksanakan kegiatan dan aktivitas untuk mencapai tujuan utama mereka yaitu untuk mengelola zakat infaq dan shadaqah, LAZ juga termasuk organisasi yang cenderung bersifat nirlaba. Artinya adalah lembaga amil zakat adalah institusi yang fungsinya untuk menyalurkan zakatnya guna kemaslahatan umat.

Fungsi lembaga amil zakat menurut Undang-Undang no.23 tahun 2011 tentang pengelolaan dana zakat, bab I tentang ketentuan umum pasal 1 ayat 8 menyatakan Lembaga Amil Zakat yang selanjutnya disingkat LAZ adalah lembaga yang memiliki tugas membantu pengumpulan, pendistribusian dan pendayagunaan zakat.

Muhammad dan Abubakar (2011:46) menjelaskan sebagai berikut : Fungsi-fungsi dasar dari organisasi zakat, 
Normalasari, et al/Jurnal Ekonomi Syariah Teori dan Terapan Vol. 6 No. 6 Juni 2019: 1178-1195; MODEL PROGRAM PEMBERDAYAAN EKONOMI DOMPET SOSIAL MADANI DALAM MEMBERDAYAKAN EKONOMI MASYARAKAT MUSLIM MELALUI PENGELOLAAN DANA ZAKAT,INFAQ DAN SHADAQAH (ZIS)

Antara lain: Pertama, mengumpulkan dari orang-orang kaya muzakki dan mendistribusikannya kembali kepada para mustahiq, Kedua, membina para muzakki agar tetap menjadi muzakki dan fakir miskin agar menjadi muzakki, Ketiga, mendata semua kelompok masyarakat baik sebagai muzakki maupun mustahiq.

\section{METODE PENELITIAN}

Metode penelitian pada umumnya merupakan cara ilmiah untuk mendapatkan data dengan tujuan dan kegunaan tertentu. Aktivitas penelitian secara subtansi ditandai oleh empat hal, yaitu adanya upaya bersifat sistematik, adanya sesuatu hasil temuan, adanya manfaat dan adanya tindak lanjut penyebarluasan temuan (Mukhadis, 2013:70).

Penelitian yang dilakukan dalam penelitian ini melalui pendekatan kualitatif. Pendekatan kualitatif dengan menggunakan metode studi kasus deskriptif dengan desain khusus tunggal (single case) karena penelitian ini hanya meneliti satu kasus yaitu Dompet Sosial Madani Denpasar.

Ruang lingkup penelitian terkait dengan rumusan masalah yaitu model pemberdayaan ekonomi masyarakat muslim di dompet sosial madani Denpasar dengan menggunakan pengelolaan dana zakat, infaq dan shadaqah, sebagai berikut : 1. Penelitian difokuskan kepada bagaimana model pemberdayaan ekonomi dompet sosial madani dalam memberdayakan ekonomi masyarakat muslim dengan menggunakan pengelolaan dana zakat, infaq dan shadaqah 2. Membatasi penelitian dengan menggunakan data-data internal Dompet Sosial Madani dalam hal penyaluran dana maupun dokumentasi penelitian.

Data yang digunakan dalam penelitian ini meliputi data primer dan data sekunder. mendefinisikan data primer adalah data yang didapat dari hasil wawancara dan observasi langsung dari lapangan dan data yang dihasilkan lebih banyak berwujud kata-kata dan tindakan dari objek penelitian. Data primer juga dapat disebut sebagai data asli. Untuk mendapatkan data primer, peneliti harus mengumpulkannya secara langsung. Dalam penelitian ini, yang menjadi sumber (informan) adalah : 1 . Manager Operasional, 2. Supervisor Program, 3. Staff Digital Marketing, 4. Penerima manfaat program pemberdayaan

Prosedur pengumpulan data merupakan langkah yang paling strategis dalam penelitian, karena tujuan utama dari penelitian adalah mendapatkan data, tanpa mengetahui teknik pengumpulan data, maka peneliti tidak akan mendapatkan data yang memenuhi standar data yang ditetapkan, dalam penelitian ini penulis menggunakanteknik pengumpulan data sebagai berikut:

1. Persiapan AwalPeneliti mengurus surat ijin penelitian skripsi pada bagian akademik Fakultas Ekonomi dan Bisnis 
Normalasari, et al/Jurnal Ekonomi Syariah Teori dan Terapan Vol. 6 No. 6 Juni 2019: 1178-1195; MODEL PROGRAM PEMBERDAYAAN EKONOMI DOMPET SOSIAL MADANI DALAM MEMBERDAYAKAN EKONOMI MASYARAKAT MUSLIM MELALUI PENGELOLAAN DANA ZAKAT,INFAQ DAN SHADAQAH (ZIS)

Universitas Airlangga sebagai pelengkap untuk ke tempat riset Dompet Sosial Madani Denpasar.

2. Observasi Langsung dan Wawancara Peneliti melakukan observasi langsung pada pihak DSM Denpasar. Peneliti melakukan observasi lapangan yang bertujuan untuk mengamati proses operasional lembaga yang fokusnya untuk memberdayakan ekonomi. Lalu peneliti menyiapkan pertanyaan yang akan diajukan kepada informan selanjutnya melakukan recording (merekam), mencatat semua data-data informasi yang sudah didapat. 3. Dokumentasi Hasil observasi dan wawancara dari objek penelitian akan didokumentasikan sendiri oleh peneliti. 4. Pengumpulan Data Peneliti mengumpulkan data primer yang diperoleh dari hasil wawancara dengan informan yang sudah dilakukan secara terbuka. Data primer didapat dari DSM Denpasar.

Teknik pengumpulan data dalam studi kasusu menurut Yin (2014) memilik enam cara yakni, dokumen, rekaman arsip, wawancara, observasi langsung, observasi partisipan, dan perangkat fisik. Pada penelitian ini juga menggunakan triangulasi sumber. Teknik ini memudahkan peneliti untuk memeriksa kredibilitas data tersebut. Karena dalam teknik ini untuk mendapatkan kebenaran yang mutlakdiperlukan berbagai metode dan sumber perolehan data yang beraneka ragam sehingga kredibilitas data yang didapatkan akan semakin kuat. Teknik keabsahan data penelitian.

\section{HASIL DAN PEMBAHASAN}

\section{Analisis Hasil Wawancara}

Hasil penelitian telah didapat melalui proses pengumpulan data yang dilakukan pada objek dan subjek penelitian. Pengumpulan data tersebut disesuaikan dengan indikator-indikator yang mengukur keberhasilan penerima manfaat sebagai pencapaian dari proses kesejahteraan yang dilakukan secara terus-menerus oleh Dompet Sosial Madani. Indikator tersebut meliputi standar hidup material, aktivitas individu, kesehatan dan pendidikan.

\section{Informan 1}

\begin{tabular}{|c|c|c|c|}
\hline Indikator & $\begin{array}{l}\text { Sebelum } \\
\text { bergabung } \\
\text { DSM }\end{array}$ & $\begin{array}{l}\text { Sesudah } \\
\text { bergabung } \\
\text { DSM }\end{array}$ & keterangan \\
\hline Materi & Kesulitan & Terbantu & Terpenuhi \\
\hline $\begin{array}{l}\text { Aktivitas } \\
\text { individu }\end{array}$ & $\begin{array}{l}\text { Tidak bekerja } \\
\text { (PHK) }\end{array}$ & $\begin{array}{l}\text { Penjual es } \\
\text { bubur }\end{array}$ & $\begin{array}{l}\text { Terbantu } \\
\text { dengan } \\
\text { program DSM }\end{array}$ \\
\hline Kesehatan & $\begin{array}{l}\text { Akses dari } \\
\text { dana pribadi }\end{array}$ & $\begin{array}{l}\text { Mendapat } \\
\text { akses gratis } \\
\text { dari DSM }\end{array}$ & Terpenuhi \\
\hline pendidikan & Terpenuhi & Terpenuhi & Terpenuhi \\
\hline
\end{tabular}

Informan 2

\begin{tabular}{|l|l|l|l|}
\hline Indikator & $\begin{array}{l}\text { Sebelum } \\
\text { bergabung } \\
\text { DSM }\end{array}$ & $\begin{array}{l}\text { Sesudah } \\
\text { bergabung } \\
\text { DSM }\end{array}$ & keterangan \\
\hline Materi & Kesulitan & Terbantu & Terpenuhi \\
\hline $\begin{array}{l}\text { Aktivitas } \\
\text { individu }\end{array}$ & $\begin{array}{l}\text { Tidak bekerja } \\
\text { (PHK) }\end{array}$ & Penjahit & $\begin{array}{l}\text { Terbantu } \\
\text { dengan } \\
\text { program DSM }\end{array}$ \\
\hline Kesehatan & $\begin{array}{l}\text { Akses dari } \\
\text { dana pribadi }\end{array}$ & $\begin{array}{l}\text { Mendapat } \\
\text { akses gratis } \\
\text { dari DSM }\end{array}$ & Terpenuhi \\
\hline pendidikan & Terpenuhi & Terpenuhi & Terpenuhi \\
\hline
\end{tabular}

Informan 3 
Normalasari, et al/Jurnal Ekonomi Syariah Teori dan Terapan Vol. 6 No. 6 Juni 2019: 1178-1195; MODEL PROGRAM PEMBERDAYAAN EKONOMI DOMPET SOSIAL MADANI DALAM MEMBERDAYAKAN EKONOMI MASYARAKAT MUSLIM MELALUI PENGELOLAAN DANA ZAKAT,INFAQ DAN SHADAQAH (ZIS)

\begin{tabular}{|l|l|l|l|}
\hline Indikator & $\begin{array}{l}\text { Sebelum } \\
\text { bergabung } \\
\text { DSM }\end{array}$ & $\begin{array}{l}\text { Sesudah } \\
\text { bergabung } \\
\text { DSM }\end{array}$ & keterangan \\
\hline Materi & Kesulitan & Terbantu & Terpenuhi \\
Aktivitas & Tidak bekerja & $\begin{array}{l}\text { Penjual } \\
\text { catering } \\
\text { (PHK) }\end{array}$ & $\begin{array}{l}\text { Terbantu } \\
\text { dengan } \\
\text { program DSM }\end{array}$ \\
\hline Kesehatan & Akses dari & $\begin{array}{l}\text { Mendapat } \\
\text { akses gratis } \\
\text { dana pribadi }\end{array}$ & Terpenuhi \\
\hline pendidikan & Terpenuhi & Terpenuhi & Terpenuhi \\
& & & \\
\hline
\end{tabular}

\section{Informan 4}

\begin{tabular}{|c|c|c|c|}
\hline Indikator & $\begin{array}{l}\text { Sebelum } \\
\text { bergabung } \\
\text { DSM }\end{array}$ & $\begin{array}{l}\text { Sesudah } \\
\text { bergabung } \\
\text { DSM }\end{array}$ & keterangan \\
\hline Materi & Kesulitan & Terbantu & Terpenuhi \\
\hline $\begin{array}{l}\text { Aktivitas } \\
\text { individu }\end{array}$ & $\begin{array}{l}\text { Tidak } \\
\text { bekerja } \\
\text { (PHK) }\end{array}$ & $\begin{array}{l}\text { Penjual } \\
\text { bakso } \\
\text { keliling }\end{array}$ & $\begin{array}{l}\text { Terbantu } \\
\text { dengan } \\
\text { program } \\
\text { DSM }\end{array}$ \\
\hline Kesehatan & $\begin{array}{l}\text { Akses dari } \\
\text { dana } \\
\text { pribadi }\end{array}$ & $\begin{array}{l}\text { Mendapat } \\
\text { akses gratis } \\
\text { dari DSM }\end{array}$ & Terpenuhi \\
\hline pendidikan & Terpenuhi & Terpenuhi & Terpenuhi \\
\hline
\end{tabular}

Informan 5

\begin{tabular}{|l|l|l|l|}
\hline Indikator & $\begin{array}{l}\text { Sebelum } \\
\text { bergabung } \\
\text { DSM }\end{array}$ & $\begin{array}{l}\text { Sesudah } \\
\text { bergabung } \\
\text { DSM }\end{array}$ & keterangan \\
\hline Materi & Kesulitan & Terbantu & Terpenuhi \\
\hline Aktivitas & $\begin{array}{l}\text { Tidak bekerja } \\
\text { (PHK) }\end{array}$ & $\begin{array}{l}\text { Penjual pizza } \\
\text { keliling }\end{array}$ & $\begin{array}{l}\text { Terbantu } \\
\text { dengan } \\
\text { program DSM }\end{array}$ \\
\hline Kesehatan & Akses dari & $\begin{array}{l}\text { Mendapat } \\
\text { akses gratis } \\
\text { dana pribadi }\end{array}$ & Terpenuhi \\
\hline pendidikan & Terpenuhi & Terpenuhi & Terpenuhi \\
\hline
\end{tabular}

Hasil penelitian telah didapat melalui proses pengumpulan data yang dilakukan pada objek dan subjek penelitian. Pengumpulan data tersebut disesuaikan dengan indikator-indikator yang mengukur keberhasilan para informan sebagai pencapaian dari proses kesejahteraan yang dilakukan secara terus menerus oleh Dompet Sosial Madani Denpasar.

Indikator-indikator tersebut meliputi standart hidup materi, aktivitas individu, kesehatan dan pendidikan. Di bawah ini disampaikan hasil rangkuman intepretasi masing-masing indikator dalam proses pengumpulan data dengan informan sebagai berikut :

\section{Indikator Materi}

Dari hasil di atas diketahui bahwa hampir kelima informan yang sebagai sumber data adalah masyarakat yang mayoritas terkena imbas dari pemutusan hubungan kerja . Hasil penelitian menunjukkan bahwa sebagian besar kelima informan sebelum mendapatkan bantuan program pemberdayaan ekonomi mengalami kesulitan keuangan dikarenakan mereka kehilangan penghasilan utama. Setelah mendapatkan bantuan program pemberdayaan ekonomi kelima informan mengalami peningkatan dalam indikator materi dan bisa memenuhi kebutuhan pokok. Meskipun peningkatan tersebut tidak naik secara tajam, namun kelima informan merasakan adanya perubahan kondisi perekonomian keluarga menjadi lebih baik jika dibandingan dengan sebelumnya.

\section{Indikator Aktivitas Individu}

Hasil penelitian menunjukkan bahwa dari kelima informan merasa terbantu setelah menerima bantuan program pemberdayaan ekonomi. Dari hasil di atas diketahui bahwa, kelima 
Normalasari, et al/Jurnal Ekonomi Syariah Teori dan Terapan Vol. 6 No. 6 Juni 2019: 1178-1 195; MODEL PROGRAM PEMBERDAYAAN EKONOMI DOMPET SOSIAL MADANI DALAM MEMBERDAYAKAN EKONOMI MASYARAKAT MUSLIM MELALUI PENGELOLAAN DANA ZAKAT,INFAQ DAN SHADAQAH (ZIS)

informan mendapatkan pekerjaan atau membuka usaha mikro yang dikelolah sendiri secara mandiri namun masih mendapatkan pendampingan dari pihak dsm, dengan cara berwirausaha kecilkecilan para informan kini bisa mempunyai pekerjaan lagi. Setelah mendapatkan bantuan program pemberdayaan mereka merasa terbantu dan mendapatkan pekerjaan yang layak dan mampu mencukupi kebutuhan pokok sehari-harinya.

\section{Indikator Kesehatan}

Hasil penelitian menunjukkan bahwa dari kelima informan bisa mendapatkan akses kesehatan dengan baik dan gratis dari Dompet Sosial Madani karena sebagai penerima manfaat secara otomatis para informan juga terdaftar di Rumah Sehat Madani yang merupakan klinik kesehatan yang dimiliki oleh DSM dan bisa di akses oleh masyarakat luas juga. Dengan demikian, pada indikator kesehatan dapat disimpulkan bahwa semua penerima manfaat atau informan menerima manfaat dan berhasil sejahtera dari adanya program pemberdayaan ekonomi dari Dompet Sosial Madani Denpasar.

\section{Indikator Pendidikan}

Hasil penelitian menunjukan bahwa dari kelima informan bisa mendapatkan atau memberikan pendidikan yang terbaik untuk putra dan putrinya karena biaya pendidikan yang ditanggung oleh pemerintah namun untuk pemenuhan kebutuhan sepeti seragam, alat tulis,sepatu dll, para informan menyatakan masih sanggup untuk memenuhi kbutuhan tersebut ketika informan di phk dan setelah menerima bantuan dari DSM informan menyatakan dapat memenuhi kebutuhannya dengan baik.

\section{KESIMPULAN DAN SARAN}

\section{Kesimpulan}

Berdasarkan analisis dan pembahasan yang telah dijelaskan dalam bab sebelumnya bahwa Dompet Sosial Madani sudah berperan dalam meningkatkan kesejahteraan para infoorman penerima manfaat dari program pemberdayaan ekonomi melalui dana bantuan zakat, infaq dan sedekah. Kesimpulan yang dapat diambil dari hasil penelitian ini yaitu;

1. Penerima manfaat bantuan semuanya mengalami peningkatan kesejahteraan di seluruh aspek indikator kesejahteraan menurut teori Stiglizt (2011).

2. Pihak DSM berperan dengan baik dalam memberikan pendampingan kepada para informan selama mengikuti program pemberdayaan ekonomi.

3. Semua informan penerima bantuan berupa modal atau peralatan yang dibutuhkan dari Dompet Sosial Madani.

4. Para informan sangat serius dalam mengikuti program ini.

5. Penerima bantuan yang mengikuti program dengan baik mengalami 
Normalasari, et al/Jurnal Ekonomi Syariah Teori dan Terapan Vol. 6 No. 6 Juni 2019: 1178-1195; MODEL PROGRAM PEMBERDAYAAN EKONOMI DOMPET SOSIAL MADANI DALAM MEMBERDAYAKAN EKONOMI MASYARAKAT MUSLIM MELALUI PENGELOLAAN DANA ZAKAT,INFAQ DAN SHADAQAH (ZIS)

peningkatan kesejahteraan diseluruh aspek indikator kesejahteraan menurut Stiglizt (2011).

Maka dapat dilihat dari hasil penelitian diatas, bahwa orang yang menerima bantuan dari program pemberdayaan ekonomi dalam berbagai macam bentuk, bisa mendapatkan kesejahteraan. Karena untuk mewujudkan kesejahteraan dibutuhkan kerjasama antara individu dengan perangkat yang lainnya dalam hal ini DSM, khususnya pada penelitian ini.

\section{SARAN}

Berikut adalah beberapa saran yang diharapkan dalam penelitian ini, yaitu:

1. Diharapkan dengan adanya hasil penelitian ini, Dompet Sosial Madani menjadi tahu hasil dari program bantuan yang di adakan dan dapat menjadikan hasil penelitian ini bahan evaluasi untuk kedepannya.

2. Diharapkan lebih memberi pengasawan terhadap seluruh penerima bantuan, agar proses jalannya program bantuan dapat dijalankan dengan maksimal.

3. Diharapkan DSM lebih selektif dan mempertimbangkan pemberian bantuan kepada para informan dan banyak terlibat dalam perkembangan dan memberi pendampingan program ini.

4. Diharapkan DSM lebih banyak mengembangkan lagi program pemberdayaan ekonomi.

\section{DAFTAR PUSTAKA}

Adi,Isbandi, Rukminto. 2008. Intervensi Komunitas Pengembangan Masyarakat Sebagai Upaya Pemberdayaan Masyarakat. Jakarta:PT. Raja Grafindo Persada.

Ali, Nuruddin, 2006, Zakat Sebagai Instrumen Dalam Kebijakan Fiskal, Jakarta, RajaGrafindo Persada.

Amiruddin et al. Anatomin Figh Zakat. Yogyakarta: Pustaka Pelajar, 2005.

Atmosudirjo, Wursanto, 2005.DasarDasarllmuOrganisasi. Yogyakarta:Andi.

Baznas (online)

http://pusat.baznas.go.id/wpcontent/perpu/UndangUndang\%2 ONo\%2023\%20Tahun\%202011\%20te ntang\%20Pengelolaan\%20Zakat.p df 20 january 2018 pkl 1.10pm).

Bps Provinsi Bali, (online) (https://bali.bps.go.id/dynamictabl e/2016/07/19/33/jumlah-danpersentase-penduduk-miskin-diprovinsi-bali-2012---2016.html 20 januari 2018 pkl 2.39pm)

Cnn Indonesia, (online) (https://www.cnnindonesia.com/g aya-hidup/20170421134200-307209237/bali-terima-penghargaandestinasi-wisata-terbaik-di-dunia 20 january 2018 pkl 2.16pm)

Dompet Sosial Madani Denpasar (online) (https://dompetsosial.id/artikels/ke menag-ri-sahkan-dompet-sosialmadani-bali-sebagai-laz-provinsi 20 january 2018 pkl 1.15pm) 
Normalasari, et al/Jurnal Ekonomi Syariah Teori dan Terapan Vol. 6 No. 6 Juni 2019: 1178-1195; MODEL PROGRAM PEMBERDAYAAN EKONOMI DOMPET SOSIAL MADANI DALAM MEMBERDAYAKAN EKONOMI MASYARAKAT MUSLIM MELALUI PENGELOLAAN DANA ZAKAT,INFAQ DAN SHADAQAH (ZIS)

Fauzia, Amelia. 2008. Faith and a State: a History of Islamic Philanthropy in Indonesia. Disertasi tidak diterbitkan. Melbourne Faculty of Arts University of Melbourne.

Hadi, $\quad 2004$. KonsepPemberdayaan,

PartisipasidanKelembagaandalam Pembangunan.

YayasanAgribisnis/PusatPengemba nganMasyarakatAgrikarya (PPMA).

Huda, Nurul, dkk. 2012. Kebijakan Publik Islami. Jakarta: Kencana Prenada Media Group.

Ife, Jim. 2002. Community Development (Sydney: Pearson Education Australia Pty Ltd.

Kamil, Syukron. 2016. Ekonomi Islam, Kelembagaan, dan Konteks Keindonesiaan. Depok: PT Rajagrafindo Persada.

Mahendrawaty, Nanih. 2001. Pembangunan Masyarakat Islam dari Ideologi, strategi, sampai Tradisi. Jakarta: Remaja Rosda Karya.

Mardi Yatma Hutomo, 2000. Pemberdayaan Masyarkat dalam Bidang Ekonomi : Tinjauan Teoritik dan Implementasi, Working Paper.

Muhammad \& Abu Bakar HM, 2011. Manajemen Organisasi Zakat, Malang: Madani.

Qardhawi, Yusuf. 1988. Figh al-Zakah. Bogor : Pustaka Lintera Antar Nusa
Qardhawi, Yusuf. 1996. Hukum Zakat. Bogor: Pustaka Lintera Antar Nusa. Republik Indonesia. Undang-Undang No 38 Tahun 1999 tentang Pengelolaan Zakat. 1999: Kementerian Agama.

-------. Undang-Undang No 23 Tahun 2011 tentang Pengelolaan Zakat. 2011: Diperbanyak oleh BAZNAS

Ryandono, Muhammad Nafik Hadi. 2008 Ekoomi ZISWAF (Zakat, Infaq, Shadaqah dan Wakaf). Surabaya: Ifdi dan Cenforis

Sekaran, Uma. 2006. Research Methods for Business. Edisi Terjemahan Jilid I. Jakarta: Salemba Empat

Sugiyono. 2011. Metode Penelitian Kuantitatif, Kualitatif dan R\&D. Bandung: Afabeta

Suharto, Edi. 2009. Membangun Masyarakat Memberdayakan Rakyat. Bandung: PT. Refika Aditama

Yin, Robert K. 2014. Study Kasus : Desain dan Metode, Terjemahan. Jakarta: PT Grafindo Persada

Yin, Robert K. 2009. Case Study Research Design and Methods Fourth Edition. California:Sage Inc.

http://kinekun.com/store/mengukurkesejahteraan-joseph-e-stiglitzamartya-senjean-paulfitoussifile:///C/User/microsoft/Dow nload/444-935-1-SM\%20.pdf 